\title{
28 Research Soure \\ Income Inequality in Obesity among US Adults 1999-2016: Does Sex Matter?
}

\section{Zare Hossein ( $\sim$ hzare1@jhu.edu )}

Johns Hopkins University Bloomberg School of Public Health https://orcid.org/0000-0002-5832-0854

Danielle D. Gaskin

Johns Hopkins University Bloomberg School of Public Health

Roland J. Thorpe, Jr.

Johns Hopkins University Bloomberg School of Public Health

\section{Research article}

Keywords: Income inequality, Income inequality, Obesity, men health, women health

Posted Date: August 11th, 2020

DOl: https://doi.org/10.21203/rs.3.rs-50079/v1

License: (c) (i) This work is licensed under a Creative Commons Attribution 4.0 International License.

Read Full License 


\section{Abstract \\ Background}

Obesity is a major public problem that varies by income and sex. However, there is little evidence that exists to determine the association between income and obesity may be moderated by sex and family income after controlling for potential covariates.

\section{Objectives}

To examine the association between income and obesity in adults ages 20 years and older and to test whether this relationship differs by sex.

\section{Methods}

Data for this study came from the 1999-2016 National Health and Nutrition Examination Surveys (NHANES). Obesity was defined by using Body Mass Index $\geq 30 \mathrm{~kg} / \mathrm{m}^{2}$, and Gini Coefficient was calculated to measure income inequality by using Poverty Income Ratio (PIR). We categorized GC in five quintiles to examine the relationship between income-inequality and obesity. For the first set of analysis, Modified Poisson regression was used in a sample of 40,917 adults with almost equal number of men and women (women's ratio was 50.6\%). Models included age, racial/ethnic groups, marital status, education, health behavior (smoking and drinking status and physical activities), health insurance coverage, self-reported health, and household structure (live alone and female-headed household).

\section{Results}

Adjusting for potential confounders, higher-income men had a higher prevalence of obesity (PR: 1.11; Cl: 1.00-1.25) compared to those with a lower-income, but women with upper middle income had a lower prevalence of obesity (PR:0.84; Cl:0.77-0.93) compared to those with a lower income.

\section{Conclusions}

The association between income inequality and obesity was consistently significant among middleincome and higher-income men than lower-income men. The same association was not found for women, women more likely to suffer from income-inequality than men.

\section{Background.}


Despite a large body of knowledge of obesity and socioeconomic status, there is relatively little known about income and income-inequality impacts on obesity and its association with sex. Studies showed that obesity prevalence varies by income [1]. Income influences health outcomes by shaping health behaviors to reduce behavioral risk factors, decreasing barriers to accessing care, moderating environmental factors or reducing inequalities [2]. Lower income population has higher rates of behavioral risk factors including smoking, drinking, obesity, and low levels of physical activity [3]. Isolating the contribution of income to health can be very difficult - if not impossible - many social risk factors including race, ethnicity, sex, geography, and educational status are connected to the income [4], people with higher incomes tend to live in healthier neighborhoods and have higher educational attainment and more social capital [5]. Income has direct and indirect effects on material conditions necessary for biological survival, social participation and opportunity to control life circumstances [6]. In spite of the aforementioned research, there is not enough literature to show how obesity changes by income inequality.

The spread of income-income inequality - opens a new argument that distribution of income may have higher impact on people and communities, with a higher income inequality in a society we expected to see a higher proportion of people in poverty $[7,8]$, and it may explain why distribution of income within and between communities are as important as the level of income [9].

Consider obesity, one of the well-known health outcome measures the prevalence of obesity in 2017-2018 was $42.4 \%$ in US adults; from 1999-2000 to 2017-2018, the age-adjusted prevalence of obesity increased from $30.5 \%$ to $42.4 \%$ [10]. Obesity prevalence fluctuates by income and socioeconomic status such as education level and maybe sex [1].

While numerous studies have investigated direct relationships between income and obesity, there is limited knowledge on income inequality and its association with obesity and between men and women. This association may operate differently by men and women, for instance income inequality is negatively associated with weight status in men who are highly integrated, but is positively associated with weight status among men who have low integration [11]. In this study, we investigate the relationship between obesity and income inequality and how this association changes between men and women.

\section{Methods.}

Data for this project came from the 1999-2016 National Health and Nutrition Examination Surveys (NHANES) [12]. NHANES is a cross-sectional survey, provides nationally representative estimates of health and nutritional status for the US population, with response rate of 73.2 between 1999-2016 [13, 14]; and a multistage probability sampling design, that makes the sample representative of "each of the four regions of the United States" [13]. The original sample between 1996-2016 was 90,394 individuals, with women ratio of $50.6 \%$. For this study we have included participants who are 20 years old and above, we dropped all pregnant women $(1,667)$ and all missing observations for Poverty Income Ratio (PIR) from the analysis, this yielded an analytic sample of 20,341 men and 20,576 women. 
Outcome Variable. Using Body Mass Index (BMI)-derived by dividing weight in kilograms by height in meters squared $\left(\mathrm{kg} / \mathrm{m}^{\wedge} 2\right)$ - we created a binary variable to identify participants who were obese (if $\mathrm{BMl}>=30)$ as the outcome variable [15].

Main Independent Variable. The main independent variable of interest is income inequality. Gini Coefficient was calculated as a measure of income inequality using Poverty Income Ratio (PIR) using Poverty Income Ratio (PIR) - a ratio of family income to poverty threshold - and Family Poverty Level. The Gini Coefficient (GC) is one of the most well-known measures of income inequality. The GC is based on the Lorenz Curve (LC) - ratio of two integration calculations on a graph of two curves, one curve representing actual inequality and other, perfect income equality. The $G C$ is defined as $A /(A+B)$ if ' $A$ ' equal zero then $\mathrm{GC}$ will be zero, which means perfect equality and if ' $\mathrm{B}$ ' was zero then the $\mathrm{GC}$ will be one, which means complete inequality [16] and Lorenz curve represents the actual distribution of income in given society [17].

We calculated the Gini Coefficient (GC) using the following equation [16].

$$
\text { Gini }=1-\sum_{i=1}^{n}\left(x_{i}-x_{i-1}\right)\left(y-y_{i-1}\right)
$$

Using the income quartile approach, we have defined a categorical variable with five quintiles; lowest quintile, second quintile, middle quintile, fourth quintile and top quintile.

Covariates. For the demographic variables we included age (years) and socioeconomic (SES) variables. SES was assessed using a binary variable for marital status ( $1=$ married, o=otherwise), education categories (less than high school graduate, high school graduate or general equivalency diploma equivalent recipient, more than high school education or some college and above). Health-related characteristics included having health insurance $(1=$ yes; $0=$ no) and self-reported health (excellent-very good, good-fair and poor). Health behavior was measured by three variables including smoking (never smoked, former smoker and current smoker), drinking (never drink, former drinker and current drinker) and physical activity, a binary variable to show have not participated in vigorous activities ( $1=$ yes; $0=$ no) during a typical week. Household structure is an important element to predict individual/household income [18], so we used a binary variable to present living alone ( $1=$ yes; $0=$ no) and female-headed household $(1=$ yes; $0=$ no $)$.

Analytic Strategy. For the first set of analysis, the mean and proportional differences between men and women for obesity, demographic, socioeconomic (SES), health-related characteristics, health behavior were evaluated using unequal t-tests. In our sample the prevalence of obesity was greater than $10 \%$; therefore, we used a weighted modified Poisson regression analysis [19-21] that produced prevalence ratios (PR) and corresponding 95\% confidence intervals(Cl)[19-21]. Six models were estimated. Model 1, was an unadjusted model examining the relationship between income level and obesity for men and 
women. Model 2 was an adjusted model 1 with including sex ( $=1$ if female) as a covariate, we ran model 3 with an interaction term of income quintile and sex. Because the interaction between income quintile and sex was significant $(p<0.001)$, we stratified the analyses by sex. These resulted to model 3 and model 4 as unadjusted and adjusted models for women and model 5 and model 6 for men, respectively.

To make our estimates as a representative of the U.S. civilian non-institutionalized population, all analyses were weighted using the NHANES individual-level sampling weights for 1999-2016 (8 waves of data) [22]. We considered P-values $<0.05$ as statistically significant and all tests were two-sided. We used STATA statistical software, version 15 to perform all analysis.

\section{Results.}

Association between income-level and obesity. Table 1 compares the distribution of the sample's characteristics for the total sample and by sex. On average about one-third of the population were obese with a significant higher rate of obesity for women $(P<.001)$. Income quintiles showed that the in comparison with men women population in our sample was in lower and middle quintiles $(23.8 \%$ women vs. $20.2 \%$ men) and men was in top quintile ( $37.5 \%$ men vs. $33.5 \%$ women).

Overall, the sample age was 47.018 .0 years old with a slightly older women population (47.9 (17.9) vs. 46.0 (18.0)). Women sample had higher percent of black non-Hispanic $(\mathrm{NH})$ and men sample had higher percent of Mexican-American with non-significant differences between percent of white $\mathrm{NH}$ and other racial/ethnic groups in both samples. The majority of the women had more than a high school education $(61.1 \%)$ and were covered by any kind of health insurance. Two-third of the women had never smoked (59.0\%), currently drank (67.0\%), were physically active (57.4), and were healthy (82.5\%). In comparison $46.5 \%$ of the men had never smoked, $85.2 \%$ were currently drank, $61.5 \%$ were physically active and $84.2 \%$ were healthy. Women were live more alone than men ( $14.9 \%$ vs. $11.8 \%)$ and only $43.7 \%$ of them were head of household in compare with $72.3 \%$ of men. Table 1 details information on women and women.

Table 1.

The association between income-inequality and obesity in women and men is displayed in Table 2 . Based on the results of the unadjusted model, rich population were less obese (PR:0.85; Cl:0.79-0.91); however, in the adjusted model, the association of income-level and obesity has disappeared (PR:0.94; Cl:0.87-1.01), this gives us this idea to run stratified model for women and men. Based on the full model (Model 2) results, the obese population was more women, black NH or Mexican American. They were married, had higher education, former smokers and drinkers, not physically active with poor health condition.

Table 2.

Model 2 is an adjusted model 1 with including sex ( $=1$ if female) as a covariate, we ran an interaction term of income inequality categories and sex. The association of income-level and obesity in the women 
sample is displayed in Table 3. Model 3 and model 4 present the association between income-inequality and obesity in women. Based upon unadjusted model women in $4^{\text {th }}$ and $5^{\text {th }}$ income-quintile group less likely to be obese (PR: 0.87; Cl: 0.81-0.93) and (PR: 0.69; Cl: 0.64-0.75), respectively. After adjusting model, the association between income-level and obesity in $4^{\text {th }}$ quintile has disappeared but remained significant in rich population (PR: 0.84; Cl: 0.76-0.93). There is negative association between income-level and obesity in women.

Model 5 and model 6 present the association between income-inequality and obesity in men. Interestingly, there is a positive association between income-inequality and obesity in men in unadjusted and adjusted models for example in $4^{\text {th }}$ quartile (PR: 1.20 ; Cl: $\left.1.08-1.32\right)$ and $5^{\text {th }}$ quartile (PR: $1.24 ; \mathrm{Cl}$ : 1.13-1.37) more likely to be obese.

Table 3.

Our adjusted models for women and men showed that individuals with obesity were black NH or Mexican American $\mathrm{NH}$, with High school graduates. They were former smoker or drinker, with no vigorous activities and fair-poor health condition.

As presented in the regression results there is different association between obesity and incomeinequality in men and women, to understand more about these differences in men and women we have used Lorenz curve and Gini Coefficient. Figure 1 - Lorenz curves - shows the Gini coefficient for income to poverty ratio in men and women population in the US between 1999-2016, to plot these curves we used average GC with jackknife standard errors. This figure compares GC between men and women and obese and non-obese population by sex.

In the panel $\mathbf{A}$, the blue solid line plots distribution of income in non-obese women and the dash-red line shows distribution in non-obese men. The blue line stays over the red line for about $40 \%$ of population and closer to the perfect equality line that means smaller income inequality within women and greater inequality within men. Interestingly, there is a different pattern in the obese population. For all income quintiles, obese women suffer more from income inequality than obese men (See panel B). For example, in obese men lower $25 \%$ of population observed only $7.1 \%$ of income and $53 \%$ of income observed by $75 \%$ of population and rest of them observed by top $25 \%$ of population. In obese women these distributions changed to $6 \%$ and $48 \%$ of first $25 \%$ and $75 \%$ of population and $52 \%$ of income observed by top $25 \%$ of population. The Gini coefficient rose from 0.295 (SE: 0.002) in men to 0.322 (SE: 0.002) in women, the jackknife standard errors for these estimators are very small and there is a significant difference between GC in men and women $(P<0.001)$.

In panels $\mathbf{C}$ and $\mathbf{D}$, we compared the GC between obese and non-obese men and women population. As presented obese women between the fifth and tenth percentile of the population (middle and higher income population) suffer more from income-inequality (panel C), GC moved between 0.342 (SE: 0.003 ) in obese women to $0.0305(0.002)$ in non-obese women. For men there is a higher income inequality in non-obese population (Panel $\mathbf{D}$ ), the red-dash-line the represent obese-men stays above the solid blue line 
(non-obese men) meaning lower income inequities for all groups of income, the GC moved from 0.285 (SE: 0.003) in obese men to 0.298 (SE:0.002) in non-obese men.

Figure 1. The Lorenz Curves and Gini Coefficients in men and women, 1999-2016

Sensitivity analysis. As a sensitivity analysis and with using the CDC approach household income was defined as a categorical variable with $\leq 130 \%$ as low-income, $>130 \%$ to $\leq 350 \%$ middle income, and $>350 \%$ as higher middle income household [1]. We found similar patterns with the original models, for example negative association between income-inequality and obesity in women with a positive association in men (See Table 4).

Table 4.

\section{Discussion.}

In this study we investigate the relationship between obesity and income inequality and how this association changes between men and women. Our findings showed that higher income inequality in men had positively associated with higher prevalence of obesity but in women income inequality has negatively associated with prevalence of obesity. For example, men in higher income groups experienced higher probability of being obese that can be explained by lower physical activities, but the pattern in women was different; increasing income in women resulted in reducing obesity - maybe because of better intake food, more exercise or changing the neighborhood.

Our literature search shows that in spite of fair amount of publication on impact of income inequality and health [23-28], and some critics that income inequality is not in fact associated with individual health outcomes [29-32], a little bit known about the impact on income inequality and obesity specifically on men and women, we found only a few articles to address income inequality and in adult men or women, for example Campbell et al. (2019) reported that income is negatively associated with weight status for men who are highly social-integrated but is positively associated with weight status among men who have lower social integration [11] and Kim et al. (2018) reported that increased income inequality and lower poverty percentage significantly associated with lower obesity rates across for men in New York counties[33].

Most of published articles on obesity and gender differences discussed impact of geographical location[34], neighborhood factors[25, 35-37], behavior and physical activities [38-40] and incomeinequality[41], food security [42], access to healthy foods [43, 44]. There is an essential need to find more about differences between men and women health especially in different income inequality groups.

There are aspects of the study that deserve comment. The data is cross-sectional; therefore, ruling out the possibility of reverse-causation is not possible, evidence shows that extent bias because of reversecausation is largely indirect [45]. NHANES has some limitations with the income variable and did not report the real income instead a categorical variable, otherwise using household income as a continuous 
variable could give us a better opportunity to find the impact of income differences instead of a proxy variable such as PIR.

There are also strengths to this study. To our knowledge, it is the first study to examine the relationship of income inequality and obesity in wide range of NHANES data (1999-2016) and between sexes. In addition, we used weighted models that make our findings nationally representative estimates, increasing the generalizability of these results. We need to notice that the Lorenz curves are unaffected by the mean of the distribution, and "they cannot be used to rank distributions in terms of social welfare, only in terms of inequality"[18]. To investigate the reasons behind the different association between men and women, we should control our models based on the geographical variables such as urban and rural area and neighborhood or at the county level to capture more variances, this is the next step in our study.

\section{Conclusions.}

The association between income and obesity operates differently for men and women. Our findings showed that higher income positively associated with prevalence of obesity in men but negatively associated with women's obesity at the same income groups, this finding in Income inequality also plays different roles between men and women, women experienced higher income-inequality, and obese women in middle and upper middle-income groups, suffer more from obesity than men in the same income groups. In obesity treatment for men and women, policy makers need to consider the redistribution of income in communities alongside with prioritizing vulnerable population. With low-income women considered as one of the most vulnerable population, most public interventions are targeted to lowincome persons. Moreover, public health interventions should target low-income women of color and even minority individuals of very high income as well, especially African Americans [46].

\section{Abbreviations}

NHANES

National Health and Nutrition Examination Surveys

BMI

Body Mass Index

PIR

Poverty Income Ratio

GC

Gini Coefficient

LC

Lorenz Curve

SES

Socioeconomic

$\mathrm{Cl}$ confidence intervals 
PR

Prevalence Ratio

SE

standard Errors

\section{Declarations}

Ethics approval and consent to participate. Not applicable

Consent for publication. Not applicable

Availability of data and materials. The dataset supporting the conclusions of this article is available in the National Health and Nutrition Examination Survey website.

https://www.cdc.gov/nchs/nhanes/about_nhanes.htm

Competing interests. The Author(s) declare(s) that there is no conflict of interest.

Funding. This work was supported by the NIMHD U54MD000214 and NHLBI (HHSN268201800012I, 1R25HL126145).

Authors' contributions. Conceptualization: Hossein Zare, Roland J. Thorpe, Jr., Data curation: Hossein Zare; Formal analysis: Hossein Zare; Funding acquisition: Darrell Gaskin, Roland J. Thorpe, Jr; Methodology: Hossein Zare, Roland J. Thorpe, Jr. Resources: Darrell Gaskin, Roland J. Thorpe, Jr; Software: Hossein Zare. Validation: Hossein Zare, Roland J. Thorpe, Jr. Writing - original draft: Hossein Zare Edit and review the final products; Hossein Zare, Danielle D. Gaskin, Roland J. Thorpe, Jr

Acknowledgements. Not applicable

\section{References}

1. Ogden CL, Carroll MD, Fakhouri TH, Hales CM, Fryar CD, Li X, Freedman DS. Prevalence of obesity among youths by household income and education level of head of household-United States 20112014. Morbidity mortality weekly report. 2018;67(6):186.

2. Pampel FC, Krueger PM, Denney JT. Socioeconomic disparities in health behaviors. Annual review of sociology. 2010;36:349-70.

3. Khullar D, Chokshi DA. Health, income, \& poverty: where we are \& what could help. Health Affairs 2018.

4. Paeratakul S, White MA, Williamson DA, Ryan DH, Bray GA. Sex, race/ethnicity, socioeconomic status, and BMI in relation to self-perception of overweight. Obesity research. 2002;10(5):345-50.

5. Kirby JB, Kaneda T. Neighborhood socioeconomic disadvantage and access to health care. Journal of health social behavior. 2005;46(1):15-31. 
6. Marmot M. The influence of income on health: views of an epidemiologist. Health Aff. 2002;21(2):31-46.

7. Gravelle $\mathrm{H}$. How much of the relation between population mortality and unequal distribution of income is a statistical artefact? Bmj 1998, 316(7128):382-385.

8. Wagstaff A: Inequality aversion, health inequalities, and health achievement: The World Bank; 2002.

9. Wilkinson R, Pickett K: The spirit level: Why greater equality makes societies stronger: Bloomsbury Publishing USA; 2011.

10. Craig M. Hales MDC, Cheryl D. Fryar. and Cynthia L. Ogden Prevalence of Obesity and Severe Obesity Among Adults: United States, 2017-2018. NCHS Data Brief No. 360 February 2020. U.S. Departmnet of Health and Human Services. Centers for Disease Control and Prevention. National Center for Health Statistics. https://www.cdc.gov/nchs/data/databriefs/db360-h.pdf. Accessed 17 July 2020.

11. Campbell $A D$, Baker EH. Do income inequalities in higher weight status depend on social integration? Soc Sci Res. 2019;83:102301.

12. NHANES. National Center for Health Statistics. National Health and Nutrition Examination Survey. Hyattsville, MD: US Department of Health and Human Services, CDC, National Center for Health Statistics. https://www.cdc.gov/nchs/nhanes/about_nhanes.htm. Accessed 17 July 2020.

13. Zipf G, Chiappa M, Porter KS, Ostchega Y, Lewis BG, Dostal J: National health and nutrition examination survey: plan and operations, 1999-2010. National Center for Health Statistics. Vital Health Stat 1(56). 2013. https://www.cdc.gov/nchs/data/series/sr_01/sr01_056.pdf. Accessed 17 July 2020.

14. NHANES: Analytic Guidelines, 2011-2014 and 2015-2016 (December 14, 2018). National Health and Nutrition Examination Survey. https://wwwn.cdc.gov/nchs/data/nhanes/20112012/analyticguidelines/analytic_guidelines_11_16.pdf. Accessed 17 July 2020.

15. NIH. Assessing Your Weight and Health Risk. National Heart, Lung and Blood Institute. https://www.nhlbi.nih.gov/health/educational/lose_wt/risk.htm. Accessed 17 July 2020.

16. Haughton J, Khandker SR. Handbook on poverty + inequality: World Bank Publications; 2009.

17. Matthew P, Brodersen DM. Income inequality and health outcomes in the United States: An empirical analysis. The Social Science Journal. 2018;55(4):432-42.

18. Deaton A: The analysis of household surveys: a microeconometric approach to development policy: The World Bank; 1997.

19. Thorpe RJ Jr, Parker LJ, Cobb RJ, Dillard F, Bowie J. Association between discrimination and obesity in African-American men. Biodemography social biology. 2017;63(3):253-61.

20. McNutt L-A, Wu C, Xue X, Hafner JP. Estimating the relative risk in cohort studies and clinical trials of common outcomes. Am J Epidemiol. 2003;157(10):940-3.

21. Zou G. A modified poisson regression approach to prospective studies with binary data. Am J Epidemiol. 2004;159(7):702-6. 
22. CDC. Centers for Disease Control Prevention. National Health and Nutrition Examination Survey: Analytic Guidelines, 2011-2014 and 2015-2016. National Center for Health Statistics, editor Atlanta, GA 2018.

23. Soobader M-J, LeClere FB. Aggregation and the measurement of income inequality: effects on morbidity. Soc Sci Med. 1999;48(6):733-44.

24. Haithcoat TL, Avery EE, Bowers KA, Hammer RD, Shyu C-R. Income inequality and health: Expanding our understanding of state-level effects by using a geospatial big data approach. Social Science Computer Review 2019:0894439319872991.

25. Lovasi GS, Schwartz-Soicher O, Quinn JW, Berger DK, Neckerman KM, Jaslow R, Lee KK, Rundle A. Neighborhood safety and green space as predictors of obesity among preschool children from lowincome families in New York City. Preventive medicine. 2013;57(3):189-93.

26. Lochner K, Pamuk E, Makuc D, Kennedy BP, Kawachi I. State-level income inequality and individual mortality risk: a prospective, multilevel study. American journal of public health. 2001;91(3):385.

27. Subramanian S, Kawachi I, Kennedy BP. Does the state you live in make a difference? Multilevel analysis of self-rated health in the US. Soc Sci Med. 2001;53(1):9-19.

28. Muller A. Education, income inequality, and mortality: a multiple regression analysis. Bmj. 2002;324(7328):23.

29. Mellor JM, Milyo J. Reexamining the evidence of an ecological association between income inequality and health. J Health Polit Policy Law. 2001;26(3):487-522.

30. Mellor JM, Milyo J. Income inequality and health status in the United States: evidence from the current population survey. Journal of Human Resources 2002:510-539.

31. Mackenbach JP: Income inequality and population health: evidence favouring a negative correlation between income inequality and life expectancy has disappeared. In.: British Medical Journal Publishing Group; 2002.

32. Kim K-t. Which Income Inequality Influences Which Health Indicators? Analysis of the Income Inequality Hypothesis with Market and Disposable Gini Indicators. Soc Indic Res. 2019;146(3):47385.

33. Kim D, Wang F, Arcan C. Peer Reviewed: Geographic Association Between Income Inequality and Obesity Among Adults in New York State. Preventing chronic disease 2018, 15.

34. Cohen SA, Cook SK, Kelley L, Foutz JD, Sando TA. A Closer Look at Rural-Urban Health Disparities: Associations Between Obesity and Rurality Vary by Geospatial and Sociodemographic Factors. The Journal of Rural Health. 2017;33(2):167-79.

35. Li X, Memarian E, Sundquist J, Zöller B, Sundquist K. Neighbourhood deprivation, individual-level familial and socio-demographic factors and diagnosed childhood obesity: a nationwide multilevel study from Sweden. Obes Facts. 2014;7(4):253-63.

36. Arcaya MC, Tucker-Seeley RD, Kim R, Schnake-Mahl A, So M, Subramanian S. Research on neighborhood effects on health in the United States: a systematic review of study characteristics. Soc Sci Med. 2016;168:16-29. 
37. Carroll-Scott A, Gilstad-Hayden K, Rosenthal L, Peters SM, McCaslin C, Joyce R, Ickovics JR. Disentangling neighborhood contextual associations with child body mass index, diet, and physical activity: the role of built, socioeconomic, and social environments. Soc Sci Med. 2013;95:106-14.

38. Kim D, Subramanian S, Gortmaker SL, Kawachi I. US state-and county-level social capital in relation to obesity and physical inactivity: a multilevel, multivariable analysis. Soc Sci Med. 2006;63(4):1045-59.

39. Beheshti R, Jalalpour M, Glass TA. Comparing methods of targeting obesity interventions in populations: an agent-based simulation. SSM-population health. 2017;3:211-8.

40. Brady C. Decreasing obesity and obesity stigma: socio-demographic differences in beliefs about causes of and responsibility for obesity. Social Sciences. 2016;5(1):12.

41. Van der Lippe T, De Ruijter J, De Ruijter E, Raub W. Persistent inequalities in time use between men and women: A detailed look at the influence of economic circumstances, policies, and culture. Eur Sociol Rev. 2011;27(2):164-79.

42. Wu C-H, Lin C-Y, Hsieh Y-P, Strong C, Meshki C, Lin Y-C, Tsai M-C. Dietary behaviors mediate the association between food insecurity and obesity among socioeconomically disadvantaged youth. Appetite. 2019;132:275-81.

43. Cooksey-Stowers K, Schwartz MB, Brownell KD. Food swamps predict obesity rates better than food deserts in the United States. Int J Environ Res Public Health. 2017;14(11):1366.

44. Gordon-Larsen P. Food availability/convenience and obesity. Advances in nutrition. 2014;5(6):80917.

45. Mehta NK, Chang VW: Obesity and mortality. In: The Oxford Handbook of the Social Science of Obesity. edn.: Oxford University Press; 2012.

46. Wilson KB, Thorpe RJ Jr, LaVeist TA. Dollar for dollar: racial and ethnic inequalities in health and health-related outcomes among persons with very high income. Preventive medicine. 2017;96:14953.

\section{Tables}

Table 1. Distribution of Selected Characteristics of US Adults over 20 years old in 1999-2016 National Health and Nutrition Examination Surveys $(\mathrm{N}=46,155)$ 


\begin{tabular}{|c|c|c|c|c|}
\hline & Men & Women & Total & p-value \\
\hline Obese (\%) & 33.1 & 36.6 & 34.5 & 0.000 \\
\hline \multicolumn{5}{|l|}{ Ratio of family income to poverty (\%) } \\
\hline $1^{\text {st }}$ quintile (Very poor) & 8.3 & 10.2 & 9.3 & 0.000 \\
\hline $2^{\text {nd }}$ quintile (Poor) & 11.9 & 13.6 & 12.8 & 0.000 \\
\hline $3^{\text {rd }}$ quintile (Middle) & 17.2 & 18.6 & 17.9 & 0.001 \\
\hline $4^{\text {th }}$ quintile (Rich) & 25.1 & 24.1 & 24.6 & 0.002 \\
\hline $5^{\text {th }}$ quintile (Very rich) & 37.5 & 33.5 & 35.5 & 0.000 \\
\hline \multicolumn{5}{|l|}{ Socio-Demographic Variables } \\
\hline Age in years at screening (Mean, SD) & $46.0(18.0)$ & $47.9(17.9)$ & $47.0(18.0)$ & 0.000 \\
\hline Female sex (\%) & - & - & 50.6 & - \\
\hline \multicolumn{5}{|l|}{ Racial/Ethnical Groups (\%) } \\
\hline White NH & 70.8 & 71.0 & 70.9 & 0.707 \\
\hline Black NH & 9.8 & 11.2 & 10.5 & 0.000 \\
\hline Mexican American & 8.5 & 6.7 & 7.6 & 0.000 \\
\hline Other & 10.9 & 11.1 & 11.0 & 0.389 \\
\hline \multicolumn{5}{|l|}{ Marital Status (\%) } \\
\hline Married & 68.3 & 60.3 & 64.2 & 0.000 \\
\hline \multicolumn{5}{|l|}{ Education (\%) } \\
\hline Less than high school & 17.5 & 16.0 & 16.7 & 0.000 \\
\hline Highs school graduate/GED & 24.5 & 22.9 & 23.7 & 0.005 \\
\hline More than high school & 58.0 & 61.1 & 59.6 & 0.000 \\
\hline \multicolumn{5}{|l|}{ Health System Variables (\%) } \\
\hline Covered by any kind of health insurance & 79.9 & 84.7 & 82.3 & 0.000 \\
\hline \multicolumn{5}{|l|}{ Health behaviors } \\
\hline \multicolumn{5}{|l|}{ Smoking Status (\%) } \\
\hline Never & 46.5 & 59.0 & 52.8 & 0.000 \\
\hline
\end{tabular}




\begin{tabular}{|lcccc|}
\hline Former & 29.0 & 21.4 & 25.1 & 0.000 \\
\hline Current & 24.5 & 19.6 & 22.1 & 0.000 \\
\hline Drinking Status (\%) & & & & \\
\hline Never & 7.6 & 17.4 & 12.6 & 0.000 \\
\hline Former & 7.1 & 15.7 & 11.5 & 0.000 \\
\hline Current & 85.2 & 67.0 & 76.0 & 0.000 \\
\hline Physical Inactivity (\%) & & & & \\
\hline Has No Rigorous or Moderate Activities & 38.5 & 42.6 & 40.5 & 0.000 \\
\hline Self-report Health (\%) & & & & \\
\hline Fair-poor (=1, if fair-poor) & 15.8 & 17.5 & 16.7 & 0.000 \\
\hline HH Structure (\%) & & & & \\
\hline Live Alone (=1, if Alone) & 11.8 & 14.9 & 13.4 & 0.000 \\
\hline Female Headed Household & 72.3 & 43.7 & 57.8 & 0.000 \\
\hline
\end{tabular}

${ }^{*} p<0.05, * * p<0.01, * * * p<0.001$

Note: We have defined quartile based on the GC calculated from ratio of family income to poverty

Table 2. Association between Income differences and Obesity in US Adults in the 1999-2016 National Health and Nutrition Examination Surveys 


\begin{tabular}{|c|c|c|c|c|}
\hline & \multicolumn{4}{|c|}{ Men and women } \\
\hline & \multicolumn{2}{|c|}{ Basic (Model 1) } & \multicolumn{2}{|c|}{ Full (Model 2) } \\
\hline & PR & $95 \%-\mathrm{Cl}$ & PR & $95 \%-\mathrm{Cl}$ \\
\hline \multicolumn{5}{|c|}{ (Ref. $1^{\text {st }}$ quintile (Very poor)) } \\
\hline $2^{\text {nd }}$ quintile (Poor) & 1.002 & [0.946]-[1.061] & 0.988 & [0.927]-[1.054] \\
\hline $3^{\text {rd }}$ quintile (Middle) & 1.014 & [0.955]-[1.077] & 1.022 & [0.960]-[1.089] \\
\hline $4^{\text {th }}$ quintile (Rich) & 0.988 & {$[0.931]-[1.048]$} & 1.043 & [0.979]-[1.110] \\
\hline $5^{\text {th }}$ quintile (Very rich) & $0.846^{\star \star \star}$ & [0.795]-[0.901] & 0.937 & {$[0.871]-[1.008]$} \\
\hline \multicolumn{5}{|c|}{ Socio-Demographic Variables } \\
\hline Age in years at screeni & $n, S E)$ & & 1.000 & [0.998]-[1.001] \\
\hline \multicolumn{5}{|l|}{ Racial/Ethnical Groups } \\
\hline Black NH & & & 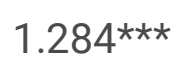 & [1.232]-[1.339] \\
\hline Mexican American & & & $1.112^{\star \star \star}$ & [1.048]-[1.180] \\
\hline Other & & & $0.829 \star \star \star$ & [0.773]-[0.890] \\
\hline \multicolumn{5}{|l|}{ Marital Status } \\
\hline Married & & & $1.070 \star \star$ & [1.022]-[1.119] \\
\hline \multicolumn{5}{|l|}{ Education } \\
\hline Highs school graduate & & & $1.171^{\star \star \star}$ & [1.112]-[1.234] \\
\hline More than high school & & & $1.097 \star \star \star$ & {$[1.044]-[1.153]$} \\
\hline \multicolumn{5}{|c|}{ Health System Variables } \\
\hline Covered by any kind of & nsurance & & $1.093^{\star \star}$ & [1.035]-[1.153] \\
\hline \multicolumn{5}{|l|}{ Health behaviors } \\
\hline \multicolumn{5}{|l|}{ Smoking Status } \\
\hline Former & & & $1.080^{\star \star}$ & [1.030]-[1.133] \\
\hline Current & & & $0.827 \star \star \star$ & {$[0.783]-[0.874]$} \\
\hline \multicolumn{5}{|l|}{ Drinking Status } \\
\hline Former & & & $1.177^{\star \star \star}$ & [1.104]-[1.256] \\
\hline Current & & & 0.971 & [0.920]-[1.025] \\
\hline
\end{tabular}




\begin{tabular}{|llll|}
\hline Physical Inactivity & & \\
\hline Has No Vigorous or Moderate Activities & $1.270^{\star * *}$ & [1.225]-[1.318] \\
\hline Self-report Health & & \\
\hline Fair-poor (=1, if fair-poor) & $1.422^{\star * *}$ & [1.364]-[1.483] \\
\hline HH Structure & & \\
\hline Live Alone (=1, if Alone) & 0.995 & {$[0.930]-[1.064]$} \\
\hline Female Headed Household & & 0.962 & {$[0.922]-[1.004]$} \\
\hline Female & & $1.045^{*}$ & {$[1.007]-[1.084]$} \\
\hline $\mathrm{N}$ & 40,917 & 36,665 & \\
\hline
\end{tabular}

${ }^{\star} p<0.05,{ }^{* \star} p<0.01,{ }^{* \star *} p<0.001$

Notes: 1) We have defined quartile based on the GC calculated from ratio of family income to poverty. 2) Variance

in number of observations is because of due to some missing.

Table 3. Association between Income differences and Obesity in US Adults in the 1999-2016 National Health and

Nutrition Examination Surveys 
Men

Basic (Model 3)

PR
Full (Model 4)

95\%-Cl
Women

Basic (Model 5)

Full (Model 6)

PR $\quad 95 \%-\mathrm{Cl} \quad \mathrm{PR} \quad 95 \%-\mathrm{Cl}$

\section{(Ref. $1^{\text {st }}$ quintile (Very}

poor))

\begin{tabular}{|c|c|c|c|c|c|c|c|c|}
\hline $\begin{array}{l}2^{\text {nd }} \\
\text { quintile } \\
\text { (Poor) }\end{array}$ & 1.081 & {$\left[\begin{array}{l}0.970]- \\
{[1.205]}\end{array}\right.$} & 1.052 & [0.938]- & 0.972 & {$\left[\begin{array}{l}0.909]- \\
{[1.039]}\end{array}\right.$} & 0.972 & {$[0.901]-$} \\
\hline $\begin{array}{l}3^{\text {rd }} \\
\text { quintile } \\
\text { (Middle) }\end{array}$ & $1.196 * \star \star$ & $\begin{array}{l}{[1.084]-} \\
{[1.319]}\end{array}$ & $1.151^{\star \star}$ & $\begin{array}{l}{[1.040]-} \\
{[1.273]}\end{array}$ & 0.934 & $\begin{array}{l}{[0.871]-} \\
{[1.000]}\end{array}$ & 0.983 & $\begin{array}{l}{[0.910]-} \\
{[1.061]}\end{array}$ \\
\hline $\begin{array}{l}4^{\text {th }} \\
\text { quintile } \\
\text { (Rich) }\end{array}$ & $1.243^{\star * \star}$ & {$[1.128]-$} & $1.212^{\star \star \star}$ & $\begin{array}{l}{[1.092]-} \\
{[1.346]}\end{array}$ & $0.866^{\star \star \star}$ & $\begin{array}{l}{[0.806]-} \\
{[0.930]}\end{array}$ & 0.974 & {$\left[\begin{array}{l}0.900]- \\
{[1.053]}\end{array}\right.$} \\
\hline $\begin{array}{l}5^{\text {th }} \\
\text { quintile } \\
\text { (Very } \\
\text { rich) }\end{array}$ & 1.138 ** & [1.034]- & 1.116 & $\begin{array}{l}{[0.998]-} \\
{[1.248]}\end{array}$ & $0.691 * \star \star$ & $\begin{array}{l}{[0.640]-} \\
{[0.746]}\end{array}$ & $0.844^{\star \star \star}$ & $\begin{array}{l}{[0.767]-} \\
{[0.928]}\end{array}$ \\
\hline
\end{tabular}

\section{Socio-Demographic Variables}

$\begin{array}{lllll}\text { Age in years at screening (Mean, } & 0.999 & {[0.997]-} & 1.0000 & {[0.998]-} \\ \text { SE) } & {[1.000]} & {[1.001]}\end{array}$

\section{Racial/Ethnical \\ Groups}

\begin{tabular}{|c|c|c|c|c|}
\hline Black NH & $1.112^{\star \star}$ & {$\left[\begin{array}{l}{[1.043} \\
{[1.185]}\end{array}\right]$} & $1.413^{\star \star \star}$ & {$\left[\begin{array}{l}{[1.341]-} \\
{[1.488}\end{array}\right]$} \\
\hline Mexican American & $1.114^{\star}$ & $\begin{array}{l}{[1.020]-} \\
{[1.217]}\end{array}$ & 1.120 ** & $\begin{array}{l}{[1.040]-} \\
{[1.207]}\end{array}$ \\
\hline Other & $0.855^{\star \star}$ & $\begin{array}{l}{[0.778]-} \\
{[0.941]}\end{array}$ & $0.811 * \star \star$ & $\begin{array}{l}{[0.743]} \\
{[0.885]}\end{array}$ \\
\hline
\end{tabular}

\section{Marital Status}

Married

$1.180 * \star * \quad[1.099]-$

1.029

[0.968]-

[1.093]

\section{Education}

Highs school

graduate/GED

\begin{tabular}{ll}
$1.208^{\star \star \star}$ & {$\left[\begin{array}{l}1.107]- \\
1.318\end{array}\right]$} \\
\hline $1.160 \star \star$ & {$[1.061]-$} \\
& {$[1.268]$}
\end{tabular}

$1.135^{\star \star \star}$

[1.064]-

[1.210]

More than high

school 
Variables

Covered by any kind of health

insurance

$1.128^{* *}$

$[1.038]-$

1.028

[0.967]-

[1.094]

\section{Health behaviors}

\section{Smoking Status}

$\begin{array}{lllll}\text { Former } & 1.076^{*} & {[1.012]-} & 1.078^{\star} & {[1.013]-} \\ & & {[1.144]} & & {[1.148]} \\ \text { Current } & 0.784^{\star \star *} & {[0.721]-} & 0.881^{* \star} & {[0.817]-} \\ & & {[0.851]} & & {[0.950]}\end{array}$

\section{Drinking Status}

$\begin{array}{lllll}\text { Former } & 1.254^{\star \star *} & {[1.119]-} & 1.163^{\star \star *} & {[1.080]-} \\ {[1.252]}\end{array}$

\section{Physical Inactivity}

Has No Vigorous or Moderate

$1.259 * \star \star$

[1.185]-

$1.273^{\star \star \star}$

[1.212]-

Activities

[1.338]

[1.338]

\section{Self-report Health}

\begin{tabular}{|c|c|c|}
\hline $\begin{array}{l}\text { Fair-poor (=1, if fair- } \\
\text { poor) }\end{array}$ & $1.364^{\star \star \star}$ & [1.273]- \\
\hline
\end{tabular}

\section{$\mathrm{HH}$}

Structure

\begin{tabular}{lcccc}
$\begin{array}{l}\text { Live Alone }(=1, \text { if } \\
\text { Alone) }\end{array}$ & 1.086 & $\begin{array}{l}{[0.984]-} \\
{[1.198]}\end{array}$ & 0.952 & $\begin{array}{l}{[0.877]-} \\
{[1.033]}\end{array}$ \\
$\begin{array}{l}\text { Female Headed } \\
\text { Household }\end{array}$ & 1.015 & $\begin{array}{l}{[0.949]-} \\
{[1.086]}\end{array}$ & 0.953 & {$[0.904]-$} \\
N & 18,518 & & 20,576 & 18,147 \\
\hline
\end{tabular}

* $p<0.05, * * p<0.01, * \star * p<0.001$

Note: Variance in number of observations is because of due to some missing.

Table 4. Association between Income differences and Obesity in US Adults in the 1999-2016 National Health

and Nutrition Examination Surveys 


\begin{tabular}{|lllllllll|}
\hline Men & & \multicolumn{5}{c|}{ Women } \\
Basic & & Full & & Basic & \multicolumn{2}{ll}{ Full } & \\
RR & Cl-95 & RR & Cl-95 & RR & Cl-95 & RR & Cl-95 \\
\hline
\end{tabular}

(Ref. Low income)

$\begin{array}{lllllllll}\text { Middle } & 1.162 * * * & {[1.093]-} & 1.143^{* * *} & {[1.072]-} & 0.921 * * & {[0.873]-} & 1.000 & {[0.947]-} \\ & & {[1.235]} & & {[1.218]} & & {[0.971]} & & {[1.057]} \\ \text { Rich } & 1.110^{* *} & {[1.040]-} & 1.107 * & {[1.025]-} & 0.729 * * * & {[0.686]-} & 0.883^{* * *} & {[0.824]-} \\ & & {[1.184]} & & {[1.196]} & & {[0.775]} & & {[0.946]}\end{array}$

\section{Socio-Demographic Variables}

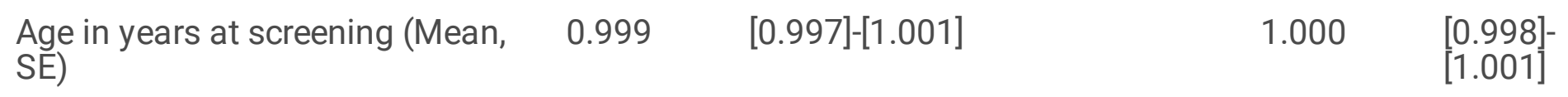

\section{Racial/Ethnical \\ Groups}

\begin{tabular}{|c|c|c|c|c|}
\hline Black NH & $1.111^{\star *}$ & [1.043]-[1.184] & $1.414^{\star \star \star}$ & $\begin{array}{l}{[1.342]-} \\
{[1.490]}\end{array}$ \\
\hline Mexican American & $1.113^{\star}$ & [1.019]-[1.216] & $1.122^{\star \star}$ & {$\left[\begin{array}{l}{[1.042]-} \\
{[1.209}\end{array}\right]$} \\
\hline Other & $0.857^{\star *}$ & [0.779]-[0.942] & $0.811^{* \star *}$ & $\begin{array}{l}{[0.743]} \\
{[0.886]}\end{array}$ \\
\hline
\end{tabular}

\section{Marital Status}

Married

$1.181^{\star \star *} \quad[1.099]-[1.268]$

1.025

[0.965]-

[1.089]

\section{Education}

Highs school

graduate/GED

$1.212^{\star \star \star} \quad[1.111]-[1.322]$

$1.135^{\star \star \star}$

[1.064]-

More than high

school

$1.159 * * \quad[1.061]-[1.266]$

1.028

[1.210]

\section{Health System}

Variables

Covered by any kind of health

insurance

$1.131^{\star \star} \quad[1.040]-[1.230]$

1.027

[0.967]-

[1.092]

\section{Health behaviors}

\section{Smoking Status}

\begin{tabular}{lllll|} 
Former & $1.077^{*}$ & {$[1.012]-[1.146]$} & $1.079 *$ & {$[1.013]-$} \\
\hline Current & $0.785^{* * *}$ & {$[0.722]-[0.853]$} & $0.883^{* *}$ & {$[0.820]-$}
\end{tabular}




\section{Drinking Status}

$\begin{array}{lcccc}\text { Former } & 1.252^{\star * *} & {[1.118]-[1.402]} & 1.162^{\star * *} & {[1.079]-} \\ {[1.252]}\end{array}$

\section{Physical Inactivity}

\begin{tabular}{|c|c|c|c|}
\hline $\begin{array}{l}\text { Has No Vigorous or Moderate } \\
\text { Activities }\end{array}$ & $1.260^{\star \star \star} \quad[1.186]-[1.339]$ & $1.275^{\star \star \star}$ & $\begin{array}{l}{[1.213]} \\
{[1.340]}\end{array}$ \\
\hline \multicolumn{4}{|l|}{ Self-report Health } \\
\hline $\begin{array}{l}\text { Fair-poor (=1, if fair- } \\
\text { poor) }\end{array}$ & $1.363^{* \star *} \quad[1.271]-[1.460]$ & $1.453^{\star \star \star}$ & $\begin{array}{l}{[1.385]} \\
{[1.524]}\end{array}$ \\
\hline
\end{tabular}

$\mathrm{HH}$

Structure

Live Alone $(=1$, if Alone)

1.084 [0.982]-[1.196]

0.952

[0.877]-

[1.034]

Female Headed

1.017 [0.951]-[1.088]

0.952

Household

Female

N 20,341

18,147

20,576

18,518

* $p<0.05, * * p<0.01, * \star * p<0.001$

Notes: 1) CDC approach household income was defined as a categorical variable with $\leq 130 \%$ as lowincome, $>130 \%$ to $\leq 350 \%$ middle income,

and $>350 \%$ as higher middle-income household. 2) Variance in number of observations is because of due to some missing.

\section{Figures}


A. Men \& Women (None Obese): 1999-2016

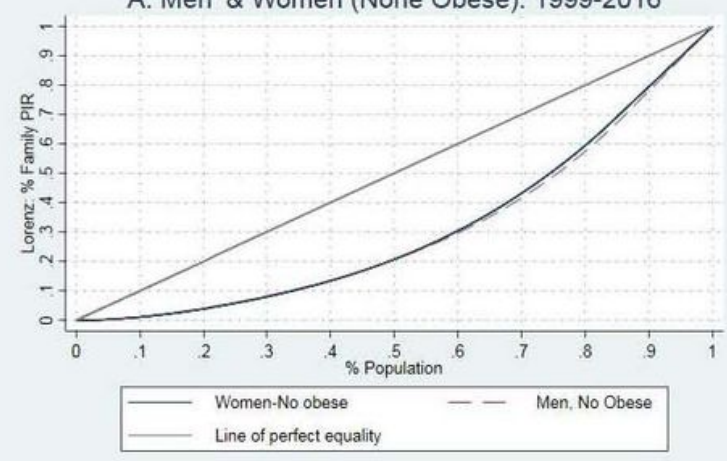

C. Women: 1999-2016

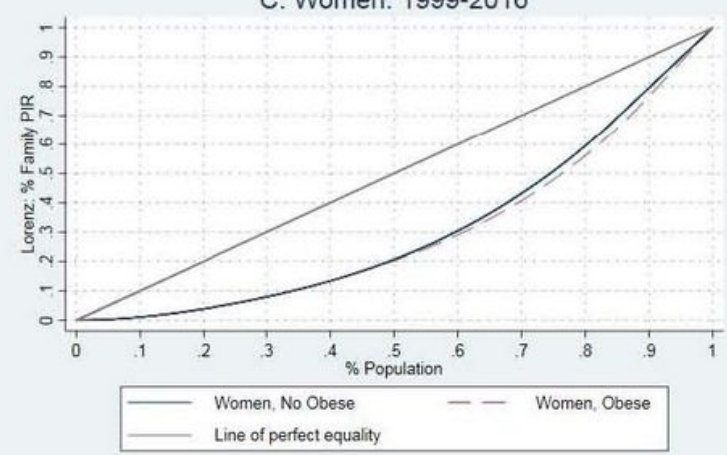

Source: NHANES: 1999-2016
B. Men \& Women(Obese) : 1999-2016

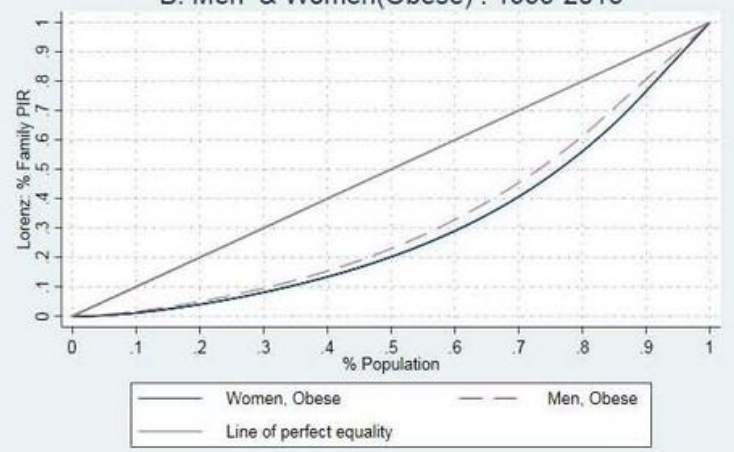

D. Men: $1999-2016$

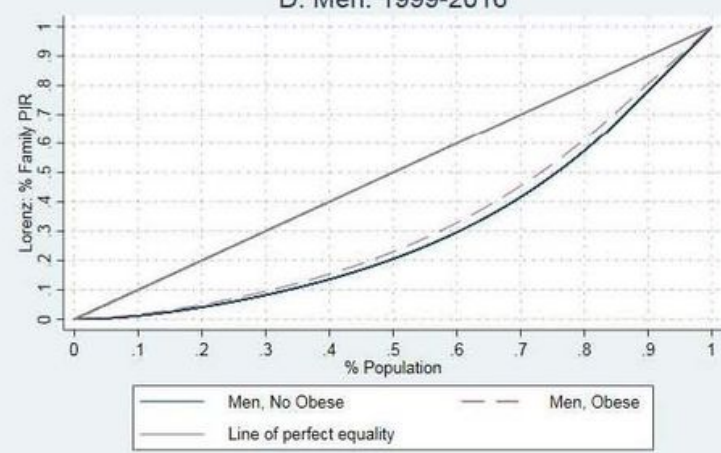

\section{Figure 1}

The Lorenz Curves and Gini Coefficients in men and women, 1999-2016

\section{Supplementary Files}

This is a list of supplementary files associated with this preprint. Click to download.

- ZARESTROBEchecklistv4combined.doc 